\title{
19 Evaluating harm-reduction initiatives in a night-time economy and music festival context
}

\author{
Laura Garius, Bethany Ward, \\ Kirsty Teague and Andromachi Tseloni
}

\subsection{Introduction}

Large licensed outdoor music festivals have emerged as part of a general expansion of licensed recreational activities in the night-time economy (NTE) and are "a major source of income and tourism" (UNESCO, 2015, p. 7). Attendees of music festivals and NTE venues have much in common; engaging in similar patterns of increased alcohol consumption and polysubstance use (Martinus et al., 2010), and at increased risk of alcohol-related harm, including hospitalization, as well as violent and sexual victimization (Garius, 2016; White Ribbon Campaign, 2016). The Modern Crime Prevention Strategy (Home Office, 2016 , p. 35) highlights alcohol as a key driver of crime and sets out a range of actions to tackle alcohol-driven crime, including increasing the safety of nighttime economy spaces. One example of a harm-reduction initiative designed to encourage positive behavior change is the "Drinkaware Crew": a group of people trained by the Drinkaware Trust to look after the welfare of young adults on a night out. Working in pairs, the Drinkaware Crew mingle with patrons to promote a positive social atmosphere and provide assistance to those who may be vulnerable as a result of excessive alcohol consumption (Drinkaware, 2016).

The aim of this study is twofold. First, it evaluates the "Drinkaware Crew" harm-reduction initiative developed as a result of Drinkaware's "Drunken Nights Out" campaign (Christmas \& Seymour, 2014) using routinely collected data. This is achieved by monitoring police recorded crime levels before and after the Drinkaware Crew intervention. Second, it evaluates the feasibility of adapting this initiative from a night-time economy to a music festival context. This is achieved by using participant observation, semi-structured interviews with "Festival Crew" members and festival stakeholders, and activity logs completed by Crew members as part of a pilot study operating across two UK-based music festivals.

Drawing on environmental criminology theories, this chapter contributes to this area of knowledge by reporting the societal impact of the Drinkaware Crew initiative using a quantitative outcome evaluation, and by assessing whether the 
Drinkaware Crew initiative is transferable beyond the NTE context in which it currently operates.

\subsection{Theoretical background}

\section{Alcohol-related harm in night-time economy venues}

Excessive alcohol consumption is known to be a catalyst for public nuisance, anti-social behavior, and interpersonal violence (De Vocht et al., 2016): an assumption supported by data (ONS, 2017b). Many factors distinctive to the NTE environment, including high concentrations of licensed premises (Newton \& Felson, 2015), the convergence of a large number of strangers and acquaintances (Hobbs, Winlow, Hadfield, \& Lister, 2005), high levels of alcohol consumption, poor venue management, and an absence of capable guardianship, cumulate in the high prevalence of crime (Elvins \& Hadfield, 2003).

The public health community have long recognized the importance of the environment when considering crime prevention (Mair \& Mair, 2003, p. 209). Felson and Clarke (1998) state that an individual's behavior is a direct product of the interaction with their physical settings and that environments can provide opportunities for crime. This approach regards crime as patterned by the routine activities of daily life, and the convergence in time and space of a motivated offender and suitable target, in the absence of capable guardianship (Cohen \& Felson, 1979). Both NTE venues and music festivals are considered crime generating locations, also referred to as "risky facilities" (Clarke \& Eck, 2003). They experience a high concentration of crime because they facilitate the convergence of large numbers of potential targets and offenders.

When selecting human targets, offenders make choices according to the perceived vulnerability of the target and their own ability to overcome the victim; revealing a degree of rationality during the commission of an offence (Felson, 1996; Rebocho \& Silva, 2014). Alcohol consumption is a particularly salient predictor of target-selection in cases of unwanted sexual attention (Kavanaugh, 2013) as personal guardianship is lowered, physical coordination is impaired, and communicative skills (beneficial for de-escalation) are diminished (Sampson \& Lauritsen, 1990). Furthermore, uncomfortable, poorly managed, and unkept venues also contribute to increased levels of interpersonal aggression (Graham, Bernards, Osgood, \& Wells, 2006) due to such environments indicating a lack of capable guardianship (Wilson \& Kelling, 1982). Formal measures of guardianship may include the presence of police, CCTV and security personnel, however, "natural supervision of the environment by ordinary individuals" (Mayhew, Clarke, Sturman, \& Hough, 1976, p. 30) minimizes opportunities for committing crime, an idea consistent with the situational crime prevention principle of "increasing the risks" and "removing the excuses" associated with committing crime (Cornish \& Clarke, 2003).

With regard to patron vulnerability and the physical space, opportunities for sexual aggression concentrate on dancefloors and other areas typified by 
movement and crowding (Becker \& Tinkler, 2015; Graham et al., 2014). In areas of crowding, aggressive sexual overtures may be more easily disguised as accidental bump-ins and may be less visible to bystanders and security staff (Graham, Wells, Bernards, \& Dennison, 2010). High patron-density can also facilitate physical opportunities for violence by increasing the convergence of potential offenders and targets, as well as psychological opportunities for violence by increasing frustration as a consequence of overcrowding and competition for services (Marsh \& Kibby, 1992).

While the primary function of bars, to facilitate interaction between strangers and acquaintances, can result in opportunities for romantic connections (Fileborn, 2017), this also gives rise to unwanted sexual attention common within NTE venues (Fileborn, 2016). The majority of patrons, both male and female, have either witnessed or directly experienced sexual aggression involving female targets and male initiators (Graham et al., 2010, 2014; Kavanaugh, 2013). Despite a growing awareness of sexual harassment (Abbey et al., 2014; Becker \& Tinkler, 2015; Brooks, 2018; Graham et al., 2014), limited attention has been paid to lower-level sexual harassment in the NTE context in terms of its scale, impact, and regulation.

Clubs and festivals have much in common, including demographic characteristics of patrons. Festival sites mirror many of the issues associated with NTE venues including alcohol-related harm, violence (Martinus et al., 2010), antisocial behavior (Mackellar, 2014) as well as forms of sexual harassment, including groping, verbal abuse and assaults (White Ribbon Campaign, 2016). Due to the parallels observed between these different environments, harm-reduction initiatives designed to reduce criminogenic opportunities in NTE venues may also be transferable to a music festival context.

\section{Drinkaware's harm reduction initiatives}

Following research by Christmas and Seymour (2014), which examined norms and rituals in the night-time economy and the role that Drinkaware could play in reducing alcohol-related harm on 'drunken nights out', Drinkaware implemented an evidence-based behavior change intervention in the form of the "Drinkaware Crew" within a number of night-time economy (NTE) venues across England and Wales. The Drinkaware Crew are specially trained staff who work in pubs, bars and clubs to reduce drunken anti-social behavior amongst 18 to 24 year olds. They are trained by Drinkaware, and employed by venues, to identify vulnerable individuals within the venue(s) and promote a positive atmosphere (Drinkaware, 2016). Operating in pairs, Crew members carry a radio to communicate with existing venue services (for example, security personnel) and a replenishable toolkit bag to facilitate patron-interaction containing wipes/tissues, pen and paper, sick bags, lollipops, and information regarding local public transport links. The Drinkaware Crew also wear Drinkaware-branded, brightly colored uniforms with "here to help" slogans; distinguishing them from formal surveillance staff (Christmas \& Seymour, 2014). The Drinkaware 
Crew align with the concept of informal guardianship (Cohen \& Felson, 1979) by providing peer-guardianship over patrons and increasing bystander awareness.

Informed by evidence that patrons at music festivals are similarly vulnerable to risks of alcohol-related harm and victimization (Martinus et al., 2010), the Drinkaware Crew initiative was adapted from the night-time economy to a music festival context. The initiative was piloted at two UK-based music festivals over Summer, 2017 (Festival A and Festival B). Ten Drinkaware Crew members operated between 2-11 p.m. across a total of seven festival days: with six Drinkaware Crew members operating at Festival A and four at Festival B. The Drinkaware "Festival Crew" also operated in pairs, wore Drinkaware-branded uniforms with "here to help" slogans, and carried radios to communicate with existing on-site services. Festival-specific adaptations for the Festival Crew included climate-specific toolkit additions (sunscreen, water bottles, ponchos) and on-site training held immediately prior to the Crew's first shift at the festivals. The training content was amended to enable Crew members to identify signs, and areas, of patron-vulnerability specific to the festival(s). Crucially, the Festival Crew were intended to act as a roaming satellite service and function as a "triage" to existing festival service-provision: including welfare, security, and first aid festival services (which are traditionally more stationary).

Drawing on both international and national literature, we anticipate that: (1) the "Drinkaware Crew" initiative is capable of reducing opportunities for alcohol-related harm within night-time economy venues; and (2) the Drinkaware "Festival Crew" can be successfully adapted from a night-time economy context to a music festival context.

\subsection{Methodology}

\section{Evaluation of the "Drinkaware Crew"}

A quantitative outcome evaluation of the original "Drinkaware crew" initiative-delivered in one NTE venue in "City A" and in two NTE venues in "City B"-was undertaken in order to assess the societal impact of the initiative operating in the night-time economy. Exploratory analysis of police recorded crime data (PRC) was utilized; including all violent and sexual crimes reported to the police recorded as having occurred within the venues of interest from approximately one year prior to the Drinkaware Crew initiative beginning, until one year after the onset (monthly violent and sexual crime counts spanning 2015 to 2017). Crime counts for the venues in which Drinkaware Crew members were active (test venues) were compared to control venues.

Unlike national victimization survey data (Crime Survey for England and Wales), or Hospital Episode Statistics, PRC data records crimes at the nighttime economy venue-level: vital when determining how environmental factors 
inform venue-level risk. PRC was obtained from two police forces, City A and City B. Data included any sexual or violent offences that happened either inside or immediately outside of the venues of interest (test and control venues) for a year prior to the onset of the initiative and for one year after its commencement. To gain more contextual information about incidents, victims, and offenders, available offence details such as time and date were requested as well as offender and victim socio-demographic information. City A and B were selected by Drinkaware based upon the dates of the initiatives' implementation in those cities.

In City A, data were available for the test venue (test venue $\mathrm{Al}$ ) in which the initiative was active, and a comparable venue in which no initiative was active-matched on venue size-which acted as a control venue to compare trends against. In City B, data were provided for two test venues (test venue B1 and B2) which had both implemented the Drinkaware Crew initiative at different time periods. There was no comparable test venue for test venue $\mathrm{Bl}$, therefore crime data regarding all other NTE venues within City B which fell under the definition of a "nightclub" were used as a control. To allow the control to be comparable to the test venues, the crime rate per 1,000 patrons (derived from venues' maximum capacities) was calculated for each venue, and then averaged. To provide a visual representation of trends in police recorded violent and sexual offences within NTE venues, trend graphs were generated. These plotted the monthly crime rate per 1,000 patrons for all test venues and for the control venue in City A, and the average of the crime rate per 1,000 patrons in all nightclubs in City B. The rate per 1,000 patrons is calculated as follows:

$$
\text { Rate per } 1000 \text { patrons }=\frac{\text { monthly crime count }}{\text { venue capacity }} * 1000
$$

Owing to the low crime counts in the dataset, when trend graphs were first generated large fluctuations were present. To combat this, three-month rolling averages were calculated to smooth the trend line, making trends easier to establish. To complement the descriptive interpretation of the trend graphs, effect size calculations were also undertaken; taking the difference between the average crime count for the period of the intervention and dividing this by the standard deviation of the pre-intervention period. This is known as a standard mean difference (Olive \& Franco, 2008). These are interpreted such that anything below 0.2 is considered a small effect size, 0.5 medium and 0.8 large. Standard mean difference is calculated as follows:

Standard mean difference $(d)=$ average pre intervention count - average intervention period count 


\section{Evaluation of the "Festival Crew"}

A process evaluation was undertaken in order to test the feasibility and acceptability of the Drinkaware Crew model in a music festival context. Process evaluations are used to "assess fidelity and quality of implementation, clarify causal mechanisms and identify contextual factors associated with variation in outcomes" (Moore et al., 2015, p. 1). The present evaluation used mixed methods to determine: (1) fidelity to the service-model; (2) frequency and scope of service delivery; and (3) the quality of implementation. Fidelity to the servicemodel, in particular adherence to the service-model, is the extent to which the delivery of a service adheres to the delivery as intended by the service-developers (Dane \& Schneider, 1998); with markers including training content and execution. The frequency and scope of service delivery captures the quantity of service provided; with markers including the volume, duration, and nature of interactions. Quality of implementation reflects the way in which the service is executed during the evaluation period; with markers including perceptions of the service's efficacy and relevance.

The process evaluation draws on (1) observation of the Festival Crew training as well as the Festival Crew in operation (70 hours of observation); (2) semistructured interviews conducted with the Festival Crew $(n=9)$; (3) semistructured interviews with key festival stakeholders, including festival welfare staff, festival organizers, senior Drinkaware Staff, and the Crew trainers $(n=10)$; and (4) Festival Crew activity log entries, in order to identify how closely the Festival Crew in operation mirrored intended service-delivery in a music festival context.

Overt participant observation and the completion of reflective diaries were undertaken by two researchers throughout the Festival Crew training/operation at both Festival A and Festival B. The majority of the data, including observations, interviews, and activity log entries were collected at the intervention sites, as is appropriate for process evaluation (Helitzer \& Yoon, 2002).

Semi-structured interviews were audio recorded and transcribed scripts were used for line by line thematic analysis: "a method for identifying, analyzing and reporting patterns (themes) within data" (Braun \& Clarke, 2006, p. 79). Adhering to the guidance of Braun and Clarke (2006), the researchers first reviewed all interview transcripts to ensure familiarity with the data. Major topics of interest were then identified and coded within the narratives and then grouped thematically (using NVivo software). Following the authors' review and definition of such themes, the final stage of analysis involved the selection of specific excerpts from the transcripts in order to illustrate the presented themes.

Festival Crew activity logs were completed online by each Crew pairing at the end of each festival day. The activity logs were designed to record the estimated volume and type of interactions provided per shift from the perspective of the Festival Crew members themselves, as well as to provide open-ended textboxes for Festival Crew members to describe any standout interactions (Drinkaware, 2017). A total of 20 independent Festival Crew log entries were submitted and analyzed over the intervention period (reporting 1,110 total 
patron interactions across both festivals). The quantitative activity log data were analyzed using IBM SPSS. Simple descriptive statistical analysis was undertaken due to limitations associated with the data. The qualitative activity log data were analyzed using thematic analysis in NVivo.

\subsection{Results}

\section{Evaluation of the "Drinkaware Crew"}

When examining the night-time economy test venue Al in City A (Figure 19.1), it can be seen that in the period between March and July 2015 (one year prior to the initiative), and in the same period of the following year (post the commencement of the initiative), that the crime rate is similar. This suggests no change due to the initiative. The increase in the crime rate in the latter part of 2015 was also mirrored in 2016, however the drop in crime experienced between October 2015 and January 2016 was not repeated in the following year whilst the initiative remained in place, thus crime records remained higher whilst the Drinkaware Crew were active. In the early months of 2016, the control venue had much higher crime counts than the test venue, however this was reversed during the implementation period, with crime higher in the test venue.

In Figure 19.2 it can be seen that during the initiative period in city B there was an increase in the crime rate in test venue $\mathrm{Bl}$. This occurred alongside the control venue remaining relatively constant. The aforementioned increase does not rise above levels prior to the initiative period. This increase is sustained after the end of the initiative period, also proceeding to rise higher than any pre-or during-initiative level. Following this however, there was a drop in the crime rate in test venue $\mathrm{Bl}$ to levels below those of the city average at the end point of the dataset. In test venue B2 a large proportion of the monthly crime counts are 0 , due to a low number of crimes occurring in the venue, possibly attributed to the smaller venue size compared with other venues analyzed. This makes it difficult to ascertain any trend, and therefore to interpret any effect of the initiative.

In City A, a small decrease in crime counts was found whilst the intervention was ongoing in test venue $\mathrm{Al}$, whereas at the control venue a moderate increase in crime was found. This would suggest a small, but positive crime reduction effect of the intervention, contrasting this with the much larger increase in the control venue suggests the effect of the intervention was larger than the standalone standard mean difference test result (Table 19.1). In City $\mathrm{B}$, an increase in crime was found within both test venues (B1 and B2) during the intervention, and within the control venues during the two separate time periods. This increase was largest in test venue $\mathrm{Bl}$, with all other venues experiencing only a small increase. Overall, this analysis would suggest an inconclusive effect of the initiative in the test venue in City A, and a negative effect at the test venues in City B. 

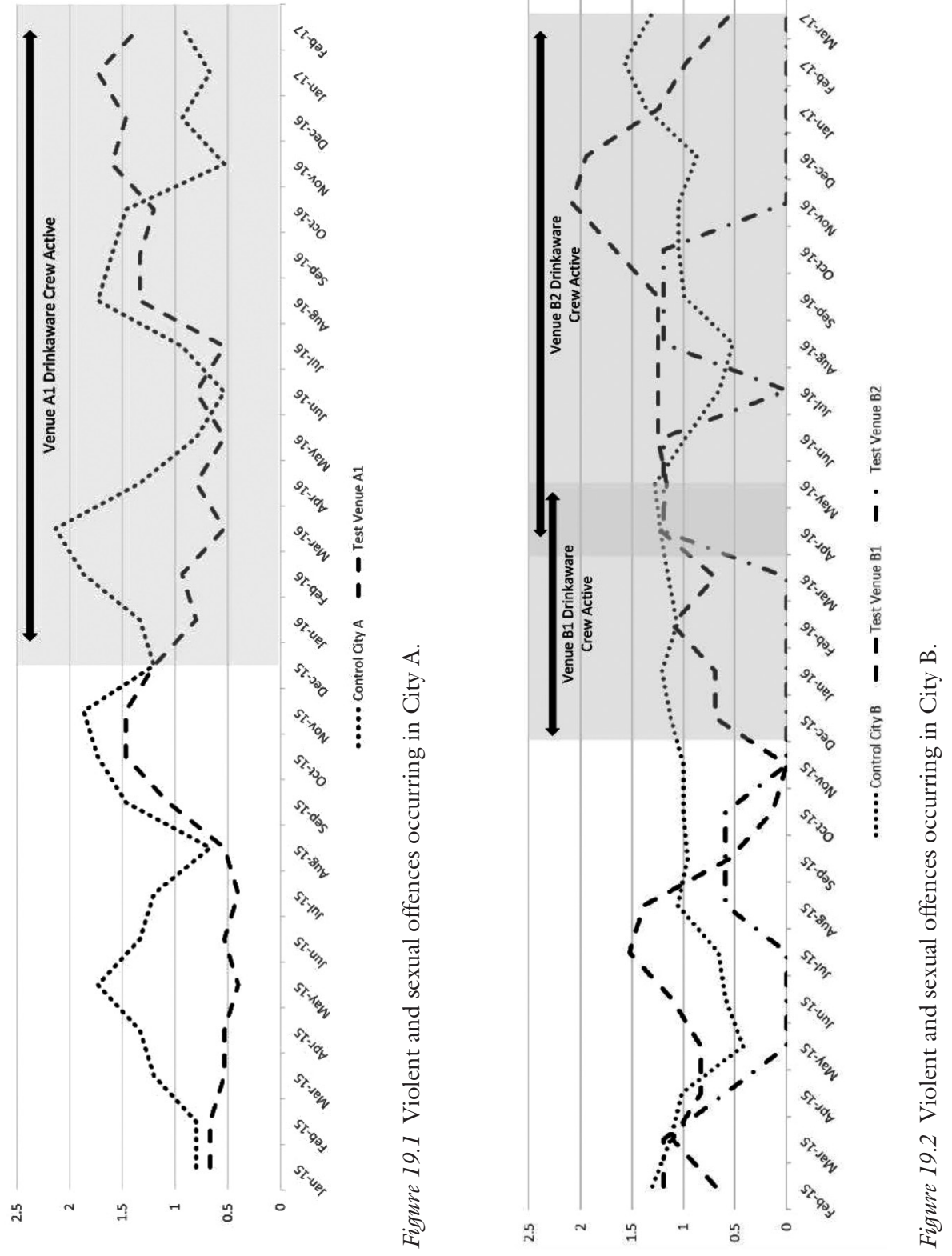
Table 19.1 Table of standard mean difference tests

\begin{tabular}{lll}
\hline Location & Venue & Standard mean difference \\
\hline City A & Test Venue Al & 0.160 \\
& Control Venue & -0.503 \\
City B & Test Venue B1 & -0.529 \\
& Control period 1* & -0.138 \\
& Test Venue B2 & -0.136 \\
& Control period 2* & -0.144 \\
\hline
\end{tabular}

Note

* In both cases this includes all venues excluding the two test venues (B1 and B2), using the time period of the intervention.

\section{Evaluation of the "Festival Crew"}

Observation of the Festival Crew training, as well as semi-structured interviews with the Festival Crew members, were used to examine fidelity to the service-model. Both observation and interview data indicate that the training successfully prepared the Festival Crew for their role in practice, and the training material/delivery was adapted appropriately to the festival context. Crew members reported feeling suitably prepared for their role, and either agreed or strongly agreed that they felt able to deliver the majority of tasks associated with the intended service: (1) mingling with patrons; (2) offering care to people in distress; and (3) providing practical support to individuals who were vulnerable as a result of alcohol intoxication, as well as those at risk of sexual harassment/unwanted sexual attention. In terms of being able to work in partnership with existing festival staff, and escalate incidents to existing staff via radio communication, confidence levels varied among the Festival Crew. The trainers' familiarity with the festival sites, as well as an on-site tour of the festival grounds, enabled the Festival Crew to identify locations of increased harm (stage fronts, queues for food/drink/toilet services, festival-site periphery). Crew interviews also highlighted that due to on-site training taking place immediately prior to shifts, they were easily able to put into practice the skills and knowledge acquired-executing the initiative as intended:

Right after [training], we went round the site, so we didn't have to wait. Everything we covered in theory we then did in practice.

(Festival Crew Member 1, Festival A)

Analysis of the Festival Crew activity logs, as well as observation of the Festival Crew in operation, were used to examine the frequency and scope of service-delivery. Across both festivals, a total of 1,110 patron-interactions were recorded in the Festival Crew activity logs. Interactions were recorded by the Crew as either "providing practical assistance" (95 percent of 
interactions), or "providing emotional support" (5 percent of interactions). The Festival Crew were also required to estimate the proportion of male and female patrons supported: with the Crew estimating 54 percent of all patrons supported to be female $(n=602)$ and 46 percent to be male $(n=508)$. Providing assistance to patrons outside of the venue, which is offered as part of the night-time economy venue initiative, was beyond the scope of service-provision in the festival adaptation due to insurance requirements. This was observed by the researchers to leave a notable gap in service-provision.

Practical support provided at the festivals primarily included information provision and supporting patrons experiencing alcohol-intoxication and climaterelated issues. Typically, patron vulnerability resulted from excessive alcohol consumption, this was as expected, and toolkits contained sick bags and water to assist in these matters. Patron-vulnerability was exacerbated by environmental conditions, for example, Festival A experienced temperatures up to $31^{\circ} \mathrm{C}$. As alcohol increases heat absorption and results in heat-related illness (Hoffman, 2001), weather-specific items (sunscreen, water bottles) were critical additions to the adapted festival toolkit.

Variation in the volume and type of Crew interactions were also observed across a number of situational factors. Service-demand was observed by the researchers to vary by time of day across both festivals: with the number of patrons requiring support concentrating later in the day, often following the headline act's exit and on patrons' departure from the site. Variation in support by music genre (categorized by the headline artist $^{l}$ ) was also observed across both festivals. Supported by the analysis of activity-log entries, a concentration of Festival Crew interactions resulted when: (1) "indie rock" headlined (24 percent of total interactions, $n=261$ ); and (2) "electronic dance music (EDM)" headlined (19 percent of total interactions, $n=215$ ).

Semi-structured interviews with key festival stakeholders, observation of the Festival Crew in operation, and Festival Crew activity logs were used to examine the quality of service-implementation. The Festival Crew recorded the escalation of 8 percent of all interactions $(n=90)$ to existing festival services (medical, welfare, or security staff), demonstrating that the Festival Crew were able to successfully manage the vast majority of interactions independently (92 percent, $n=1,020$ ); providing relief to existing festival services as intended. Semistructured interviews conducted with festival stakeholders confirmed that the Festival Crew were successfully implemented as a "triage" service; specifically, as a mobile outreach satellite operation due to other services remaining largely static. Therefore, the Festival Crew effectively occupied a unique gap in festivalstaff infrastructure:

I would love to have the Crew integrated into a common process that we put together through planning ... certainly with the medics and the security and welfare team and the dedicated Drinkaware Crew.

(Festival Organizer, Festival A) 
It is helpful ... having people as eyes and ears out there is amazing. I think it's [Festival Crew] a brilliant idea to do that and, given more resources, we'd be out there, but we haven't got them and we're not going to get them, so we focus on where we can work effectively, which is in this tent.

(Welfare Staff Member, Festival A)

Furthermore, the approachability of the Festival Crew, conveyed by the "here to help" uniform design and friendly interaction-style, successfully distinguished the Festival Crew from more formal measures of guardianship at the festival.

Most of the interactions that we have, besides the ones where we go and check on people, people see us walking past them and they see the T-shirts and they literally scream, "here to help" and we turn around. They call us. That's how we're identifiable.

(Festival Crew Member 1, Festival A)

Most people are really apprehensive about going to security ... if you've got a friendly face or somebody on the ground that could provide a bit help; it's amazing. People feel a lot more comfortable to talk to us.

(Festival Crew Member 3, Festival A)

\subsection{Discussion}

In assessing the impact of the "Drinkaware Crew" initiative in night-time economy venues based on police recorded crime data (PRC), it can be concluded that there was an increase in recorded crime in test venues in City B and an inconclusive effect on recorded crime in the test venue in City A. This was an unexpected result with regards to existing literature, which predicts a reduction in alcohol-related harm resulting from increased venue-level guardianship (Cohen \& Felson, 1979). However, there is also a body of literature which demonstrates that increases in PRC may reflect changes in recording and reporting practicesrelated to changing police practices as well as changes in public attitudes-as opposed to reflecting true changes in crime (Smith \& Allen, 2004).

There is a reliance upon both the reporting of crime by victims, and correct recording of crimes by police for offences to be included in PRC. Moreover, violent and sexual offences are the least likely crime types to be correctly recorded by the police, with errors in 67 percent of violent offences, and 74 percent of sexual offences (HMIC, 2014). ONS (2017a) analysis found a 22 percent increase in police recorded violence against the person offences from 2015 to 2016 , and a 20 percent increase in police recorded sexual offences, despite no statistically significant change in such crimes being found in the Crime Survey for England and Wales (CSEW) victimization survey (ONS, $2017 b)$. Therefore, we may attribute some of the apparent crime increases shown in the data to be evidence of improved and increased reporting to police and improved police recording practices. 
Analysis of the CSEW undertaken by the ONS reveals that less serious offences are the least likely to be represented in PRC (ONS, 2017b). A report by the Ministry of Justice, the Home Office, and the ONS (2013) found that only 15 percent of victims of the most serious sexual offences reported the incident to the police, and we may deduce from previous analysis that this percentage may be lower for victims of less serious assault. Improving national attitudes has increased reporting and recording of violent and sexual assaults (ONS, $2017 \mathrm{~b}$ ), and it is hypothesized that this may have occurred at a venue level. This may therefore account for some of the disparity between the test and control venues.

In assessing the implementation of the "Festival Crew" initiative at two large-scale music festivals in 2017, the initiative was found to be implemented successfully as a harm-reduction service; enhancing existing festival operations. The Festival Crew operated as a roaming service and were observed assisting distressed patrons and being actively vigilant for vulnerable patrons around the perimeters of the site who may be less visible or less able to actively seek assistance. Whilst intoxicated, adult patrons (approximately 18-24 years old) made up a large proportion of patron interactions (similar to the original, night-time economy based "Drinkaware Crew" interactions), the Festival Crew also supported older intoxicated patrons, children in distress, and offered support tailored to weather-dependent scenarios.

Support volume and type were recorded by the activity logs as varying by a number of situational factors (day of the week, musical genre, patrondemography). Whilst the increased support of female patrons mirrors existing literature (Graham et al., 2014), diversity in the age of patrons supported was greater than expected. A diversification in patronage has been identified within licensed contexts previously (Garius, 2016), however, a large presence of children, and corresponding Crew interactions pertaining to lost children and promoting child safety, were not anticipated in the scope of service delivery.

Activity log analysis indicated that 80 percent of patrons supported on the nostalgic-pop headlined festival-day were female $(n=32)$. Such variation could reflect variation in festival patronage. Newton and Felson (2015, p. 5) stress that "the denominators of crime (rates) are an essential component to aid our examination of crime risk". Figures regarding total patron attendance (and patron socio-demographic characteristics) by festival/festival-day (through which comparable support rates per population could be calculated) were unavailable.

The total number of patron interactions recorded in the activity logs $(1,110$ interactions) was observed by the researchers as being an underestimation of the total support given. A number of limitations were associated with the design/ completion of the activity logs, including that separate incidents/interactions were not recorded individually. Instead, totals by overall support category (practical support, emotional support) were estimated by Festival Crew members. Inferential statistical analysis of these data was therefore not possible. 


\subsection{Conclusion and recommendations}

Existing literature, as well as government strategies such as the Modern Crime Prevention Strategy (Home Office, 2016), highlight the necessity of harmreduction initiatives focusing on the immediate social (as well as physical) environment in order to reduce opportunities for alcohol-related harm and victimization (Wortley, 1998; Graham et al., 2010). However, it is imperative that we are also able to evaluate these schemes (Sanderson, 2002).

When evaluating the impact of the Drinkaware Crew initiative using routinely collected data (police recorded crime) for City A, the data suggest an increase in all crime types during the initiative period. In City B, in test venue $\mathrm{Bl}$, the average number of crimes per month was lower during the initiative period than the pre-initiative period, however it continuously rose during the initiative period. This rise continued post the termination of the initiative. Test venue B2 in City B did not provide much evidence of an impact of the initiative due to the very low crime rates in the venue, with only seven such events occurring throughout the entire data series. In conclusion, although data analysis suggests that the impact of the "Drinkaware Crew" has not reduced crime within the venues studied, this paper does not conclude that the initiative had the impact of increasing crime in NTE venues. Rather, it concludes that the data are unreliable for the purpose of evaluation of this initiative due to a series of limitations associated with PRC data: this is in addition to existing evidence that sexual crime, particularly "lower-level" sexual crime, is especially subject to reporting/recording practices (ONS, 2017b).

The low proportion of offences reported to, and recorded by, the police not only reduces the reliability of the evaluation's results, but also affects the type of analyses that can be undertaken. Inferential analysis could not be undertaken, thus the conclusions that can be drawn from these analyses are limited. Additional limitations to using PRC data include difficulties in gaining access to venue-level crime. Whilst we were successful in obtaining data in two (Cities A and B) out of three data requests, this was a lengthy process lasting 4-6 months. In addition, due to forces having different recording practices and data formats, the preparation of data was complex.

In order to carry out more conclusive analyses, alternative data sources must be considered, with one option being venue-acquired data. It is anticipated that venues would maintain information regarding incidents occurring within the venues. These are expected to capture more low-level incidents that are not captured by PRC data. It is, however, unlikely that these venuerecords would capture all opportunistic predation incidents that occur in areas of low visibility. An issue with the use of these data would be the formatting of venue-records into a usable format. It is expected that this would be a time-consuming process for each venue included in an evaluation-and as this is not a routinely collected data source, it would require both test venues' compliance and the recruitment of control venue(s) in order to test the initiative's effectiveness. 
Whilst it is not possible from the process evaluation of the Festival Crew initiative to draw final conclusions in relation to outcomes, or indeed impact, the potential for impact was evident. Throughout the observation period, festival-goers utilized the Drinkaware Crew to reduce alcohol-related harm for both themselves and others. This is also supported by interviews with existing festival stakeholders. Recommendations to further improve the adaptation of the initiative to the festival context include: (1) heightened visibility, both in terms of a social media presence to promote the service at the festivals and an increased Festival Crew-to-patron ratio; (2) further integration of Crew into existing staff infrastructures; (3) a defined Drinkaware space at festivals to facilitate on-site training and store kit, and to protect refreshment breaks for Festival Crew without disruption from festival patrons; and, finally, (4) measures to improve data collection (activity log validity and reliability).

Festival Crew activity log data provided evidence of high levels of engagement with patrons throughout the intervention period. However, the activity logs were limited in their ability to capture valid, reliable measures of the scope and scale of service-provided, and the impact this initiative may have had. A preexisting artificial cap of 80 incidents had been applied to each support category per Crew pairing per day to minimize anomalous results via the activity log online-portal. However, Festival Crew member interviews, and researcherobservation, found that this cap was often exceeded due to the large demand for service at the festival(s). Researcher-observation revealed a lack of consistency between Festival Crew members' recording of support provided. Whilst some Crew members recorded "low-level" interactions within their activity log, others chose not to record more "minor" events/interactions. This restricts the reliability of entries between the Crew members.

Recommendations to improve activity log accuracy include: (1) incorporating user-friendly, printed guides/templates containing interaction inclusion/ exclusion criteria within the toolkit; (2) encouraging completion of logs in stages throughout shifts; and (3) dedicating a greater proportion of training to log-completion best-practice. Possible solutions to improve data collection include the use of clickers to count the number of patron interactions, or a live activity-log app completed via Festival Crew members' mobile phones. Given the current limitations of Festival Crew activity log data, the availability and suitability of festival venue-acquired data should be explored in order to evaluate demand for service-provision.

Clarity is required when evaluating behavior change initiatives to ascertain whether such initiatives do indeed result in more "optimal outcomes" than other intervention-types (Kosters \& Van der Heijden, 2015). However, this chapter concludes that the data currently available are unable to definitively establish outcomes-although demand for service-provision is clear in both night-time economy and music festival contexts. Licensed venues are required to adhere to the following licensing objectives under The Licensing Act 2003: the prevention of crime and disorder, public safety, the prevention of public nuisance, and the protection of children from harm. Inclusion of the Drinkaware Crew initiative 
in licensed venues allows NTE venues, and festivals, to meet their responsibility of holding a license to sell alcohol. Similarly, the Modern Crime Prevention Strategy (Home Office, 2016, p. 33) emphasizes that those with a stake in the night-time economy have a responsibility to work collaboratively to deliver such behavior change interventions to "ensure that people can enjoy a safe night out without fear of becoming a victim of alcohol-related crime or disorder". However, initiative developers must work closely with the venues in which they operate in order to effectively evaluate initiatives-given the need for harmreduction schemes to be evidence-based and given the limitations of existing routinely collected data.

\section{Funding}

This work was supported by the Drinkaware Trust. Drinkaware is primarily funded by voluntary and unrestricted donations from UK alcohol producers, retailers and supermarkets, based on an agreement between the UK government and the alcohol industry. The funders of Drinkaware have no involvement in or influence over the activities of the charity which is governed by an independent Board of trustees. Drinkaware had no involvement in the analysis and findings reported in this work.

\section{Note}

1 Headline artists across both festivals included (Nostalgic pop (4 percent of total interactions), alternative ( 9 percent), punk (13 percent), modern pop (15 percent), nostalgic rock (16 percent), EDM (19 percent), indie rock ( 24 percent), (each musical genre played for an equal amount of time-one festival day).

\section{References}

Abbey, A., Wegner, R., Woerner, J., Pegram, S. E., \& Pierce, J. (2014). Review of survey and experimental research that examines the relationship between alcohol consumption and men's sexual aggression perpetration. Trauma, Violence, \& Abuse, 15, 265-282.

Becker, S., \& Tinkler, J. (2015). "Me getting plastered and her provoking my eyes" young people's attribution of blame for sexual aggression in public drinking spaces. Feminist criminology, 10, 235-258.

Braun, V., \& Clarke, V. (2006). Using thematic analysis in psychology. Qualitative Research in Psychology, 3, 77-101.

Brooks, V. (2018). Sex: Why We Need to Research it More Post \#MeToo. The Conversation. https://theconversation.com/sex-why-we-need-to-research-it-more-post-metoo101994.

Christmas, S., \& Seymour, F. (2014). Drunken Nights Out: Motivations, Norms and Rituals in the Night-Time Economy. London: Drinkaware. www.Drinkaware.co.uk/ media/1567/Drinkaware_drunken-nights-out-report_full-report_vfinal-pdf-versionwithout-page-breaks-_dec-2014-amend.pdf.

Clarke, R. V., \& Eck, J. E. (2003). Become a Problem-solving Crime Analyst: In 55 Small Steps. London: Jill Dando Institute of Crime Science.

Cohen, L. E., \& Felson, M. (1979). Social change and crime rate trends: a routine activity approach. American Sociological Review, 44, 588-608. 
Cornish, D. B., \& Clarke, R. V. (2003). Opportunities, precipitators and criminal decisions: a reply to Wortley's critique of situational crime prevention. In M. Smith \& D. B. Cornish (Eds.). Theory for Situational Crime Prevention, Crime Prevention Studies, Vol. 16. Monsey, New York: Criminal Justice Press, 41-96.

Dane, A. V., \& Schneider, B. H. (1998). Program integrity in primary and early secondary prevention: are implementation effects out of control? Clinical Psychology Review, $18(1), 23-45$.

De Vocht, F., Heron, J., Campbell, R., Egan, M., Mooney, J., Angus, C., Brennan, A., \& Hickman, M. (2016). Testing the impact of local alcohol licencing policies on reported crime rates in England, Journal of Epidemiology and Community Health, 71, $137-145$.

Drinkaware. (2016). 'Drunken Nights Out'-Campaign Summary. www.drinkaware.co. $\mathrm{uk} /$ research/our-research-and-evaluation-reports/drunken-nights-out-campaignsummary/.

Drinkaware. (2017). Helping Create a Safer Night-Time Economy: Drinkaware Crew Pilot. London: Drinkaware.

Elvins, M., \& Hadfield, P. (2003). "West End stress area. Night-time economy profiling: a demonstration project". Department of Sociology and Social Policy, University of Durham, Durham.

Felson, R. B. (1996). Big people hit little people: sex differences in physical power and interpersonal violence. Criminology, 34, 433-452.

Felson, M., \& Clarke, R. V. (1998). Opportunity Makes the Thief. Police Research Series, Paper 98. Policing and Reducing Crime Unit, Research, Development and Statistics Directorate. London: Home Office.

Fileborn, B. (2016). Reclaiming the Night-time Economy: Unwanted Sexual Attention in Pubs and Clubs. Basingstoke: Palgrave Macmillan.

Fileborn, B. (2017). 'Staff can't be the ones that play judge and jury': young adults' suggestions for preventing unwanted sexual attention in pubs and clubs. Australian o New Zealand Journal of Criminology, 50, 213-233.

Garius, L. (2016). Opportunities for Physical Assault in the Night-Time Economy in England and Wales, 1981-2011/12 (Doctoral dissertation, Loughborough University).

Graham, K., Bernards, S., Osgood, D. W., \& Wells, S. (2006). Bad nights or bad bars? Multi-level analysis of environmental predictors of aggression in late-night large-capacity bars and clubs. Addiction, 101, 1569-1580.

Graham, K., Wells, S., Bernards, S., \& Dennison, S. (2010). "Yes, I do but not with you": qualitative analyses of sexual/romantic overture-related aggression in bars and clubs. Contemporary Drug Problems, 37, 197-240.

Graham, K., Bernards, S., Wayne Osgood, D., Abbey, A., Parks, M., Flynn, A., Dumas, T., \& Wells, S. (2014). "Blurred lines?" Sexual aggression and barroom culture. Alcoholism: Clinical and Experimental Research, 38, 1416-1424.

Helitzer, D., \& Yoon, S. (2002). Process evaluation of the adolescent social action program in New Mexico. In A. Steckler \& L. Linnan (Eds.). Process Evaluation for Public Health Interventions and Research (pp. 83-109). San Francisco: Jossey-Bass.

HMIC (2014). Crime-recording: making the victim count. The final report of an inspection of crime data integrity in police forces in England and Wales. Her Majesty's Inspectorate of Constabulary, November 2014. www.justiceinspectorates.gov.uklhmic/ wpcontent/uploads/crime-recording-making-the-victim-count.pdf.

Hobbs, D. Winlow, A., Hadfield, P., \& Lister, S. (2005). Violent hypocrisy: governance and the night-time economy. European Journal of Criminology, 2, 161-183.

Hoffman, J. L. (2001). Heat-related illness in children. Clinical Pediatric Emergency Medicine, 2, 203-210. 
Home Office (2016). Modern Crime Prevention Strategy. London: Home Office. www. gov.uk/government/publications/modern-crime-prevention-strategy.

Kavanaugh, P. R. (2013). The continuum of sexual violence women's accounts of victimization in urban nightlife. Feminist Criminology, 8, 20-39.

Kosters, M., \& Van der Heijden, J. (2015). From mechanism to virtue: evaluating nudge theory. Evaluation, 21, 276-291.

Mackellar, J. (2014). Event Audiences and Expectations. Oxon: Routledge.

Mair, J. S., \& Mair, M. (2003). Violence prevention and control through environmental modifications. Annual Review of Public Health, 24, 209-225.

Marsh, P., \& Kibby, K. (1992). Drinking and Public Disorder. Oxford: Alden Press.

Martinus, T., McAlaney, J., McLaughlin, L. J., \& Smith, H. (2010). Outdoor music festivals: cacophonous consumption or melodious moderation? Drugs: Education, Prevention and Policy, 17, 795-807.

Mayhew, P., Clarke, R. V., Sturman, A., \& Hough, J. M. (1976). Crime as Opportunity. London: Her Majesty's Stationery Office.

Moore, G. F., Audrey, S., Barker, M., Bond, L., Bonell, C., Hardeman, W., Moore, L., O'Cathain, A., Tinati, T., Wright, D., \& Baird, J. (2015). Process evaluation of complex interventions: Medical Research Council guidance. British Medical Journal, 350, 1-7.

Newton, A., \& Felson, M. (2015). Editorial: crime patterns in time and space: the dynamics of crime opportunities in urban areas. Crime Science, 4, 1-5.

Olive, M. L., \& Franco, J. H. (2008). (Effect) size matters: and so does the calculation. The Behavior Analyst Today, 9, 5-10.

ONS (2013). An Overview of Sexual Offending in England and Wales. Newport: ONS. https://assets.publishing.service.gov.uk/government/uploads/system/uploads/ attachment_data/file/214970/sexual-offending-overview-jan-2013.pdf.

ONS (2017a). User Guide to Crime Statistics for England and Wales. Newport: ONS. http://doc.ukdataservice.ac.uk/doc/8140/mrdoc/pdf/8140_userguidecrimestats.pdf.

ONS (2017b). Overview of Violent Crime and Sexual Offences. Newport: ONS. www.ons. gov.uk/peoplepopulationandcommunity/crimeandjustice/compendium/focusonviolentcrimeandsexualoffences/yearendingmarch2016/overviewofviolentcrimeandsexualoffences.

Rebocho, M. F., \& Silva, P. (2014). Target selection in rapists: the role of environment and contextual factors. Aggression and Violent Behavior, 19, 42-49.

Sampson, R. J., \& Lauritsen, J. L. (1990). Deviant lifestyles, proximity to crime, and the offender-victim link in personal violence. Journal of Research in Crime and Delinquency, 27, 110-139.

Sanderson, I. (2002). Evaluation, policy learning and evidence-based policy making. Public Administration, 80, 1-22.

Smith, C., \& Allen, J. (2004). Violent Crime in England and Wales. London: Home Office.

UNESCO. (2015). Festival Statistics: Key Concepts and Current Practices. 2009 UNESCO Framework for Cultural Statistics Handbook No. 3. Montreal, Canada: UNESCO. www.uis.unesco.org/culture/Documents/fcs-handbook-3-festival-statistics.pdf.

White Ribbon Campaign (2016). Safe Music: Making Gigs and Festivals Safer for Women. A Report by The White Ribbon Campaign. www.whiteribboncampaign.co.uk/ node $/ 273$.

Wilson, J. Q., \& Kelling, G. L. (1982). Broken windows. Atlantic Monthly, 249, 29-38.

Wortley, R. (1998). A two-stage model of situational crime prevention. Studies on Crime and Crime Prevention, 7, 173-188. 